\title{
Cytomorphological Behaviour and Origin of Unusual Chromosomal Variants in Pearl Millet (Pennisetum americanum (L.) K. Schum)
}

\author{
R. Sai Kumar, U.P. Singh, R. M. Singh and R. B. Singh ${ }^{1}$ \\ Department of Genetics and Plant Breeding, \\ Institute of Agricultural Sciences, \\ Banaras Hindu University, \\ Varanasi-221005, India
}

Accepted May 19, 1986

Cytogenetic manipulation induced in a crop may be useful in understanding the degree of tolerance of a crop to chromosomal changes, isolation of mutants, study of phylogeny and genetic nature of traits and productions of new cytogenetic stocks useful to the breeders. Cytogenetic studies on aneuploids (Sears 1956, Riley and Law 1965) are highly useful in crop improvement. Aneuploids have been used extensively in genetical and plant breeding researches (Hermsen 1970, Khush 1973, Rajhathy 1975 and Meijer and Ahloowalia 1981) and trisomics are the main aneuploids produced in case of diploids.

In addition to different trisomics, other types of chromosome variants have been isolated in the progeny of triploid, translocation and other cytogenetical stocks of different plants (Gill et al. 1970, Jauhar 1970 in pearl millet; Ahloowalia 1966, 1970, 1971, 1982 in ryegrass; Ellerstrom and Sjodin 1966 in red clover; Rommel 1963 in barley and sugarbeet; Hagberg and Ellerstrom 1959 and Aastveit 1963 in rye).

\section{Materials and methods}

Several simple interchange heterozygotes induced by treating the seeds with $30 \mathrm{kR}$ gamma rays, have been used for isolation of different aneuploids. Tetraploidy in pearl millet was induced and triploids were isolated in the progeny of tetraploids vs. diploids and reciprocal crosses. Two triploids $(3 n=21)$ from tetraploid vs. diploid crosses and one from diploid vs. tetraploid crosses were isolated during the present investigation. One more triploid was also isolated in the progeny of diploid spontaneously. This could have arisen through formation of unreduced gametes and their subsequent fertilization with normal pollen. In the progeny of triploid vs. diploid cross, 41 trisomics, 4 double trisomics, 1 tetra-trisomic and 1 hypotriploid were isolated. A hypertriploid (22-chromosomes variant) was also identified in the progeny of primary trisomics possibly due to formation of unreduced egg cell having 15 chromosomes and its fertilization with normal pollen. Three chromosome variants viz., 27-chromosome type (hypotetraploid) and 29 and 30-chromosome types (hypertetraploid) were selected in the population of $\mathrm{C}_{2}$ generation which consisted of more than one thousand tetaploid plants of pearl millet.

Material for cytological study was fixed in a freshly prepared Carnoy's fluid for 24 hours at room temperature and then stored in $70 \%$ alcohol until further study. Anthers were squashed in $2.0 \%$ acetocarmine and fresh preparations were used for study of various chromosome configurations and microphotography.

1 Present address: Prof. R. B. Singh, Regional Plant Production and Protection Officer, FAO office for Asia and Pacific, Phra Atit Road, Maliwan Manson, Bangkok-2, Thailand. 
Result

Double trisomic

Four double trisomics were isolated in the progeny of two triploids of pearl millet and were distinguishable from their deploid sibs by their reduced plant height, leaf length, width, panicle length and girth. But number of tillers in the double trisomics derived from the first triploid was considerably high in comparison to those isolated from the second triploid. Of these, only two double trisomics could be studied cytogenetically. The fequency of cells with varying chromosomes configurations revealed that about $55 \% \mathrm{PMCs}$ of diakinesis and $76 \%$ of MI formed $5^{\text {II }}+2^{\text {III }}$ in the first double trisomic while only $10 \%$ of PMCs were seen with such association in second case (Table 1). The frequency of cells with $7^{\mathrm{II}}+2^{\mathrm{I}}$ was maximum (54\%) followed by $40 \%$ of cells with $6^{\mathrm{II}}+1^{\mathrm{III}}+1^{\mathrm{I}}$ in second double trisomic (Fig. 1). At AI 8: 8 disjunction was noticed in $56 \%$ and $40 \%$ cells of first and second double trisomics, respectively (Table 2). But the high incidence of univalents has probably caused the frequent distribution (48\%) of 9: 7 chromosomes (Fig. 3) and formation of univalent laggard in second trisome.

Table 1. Variation in chromosome associations in different aneuploids of pearl millet (pooled data of diakinesis and metaphase I)

\begin{tabular}{lccccccc}
\hline \hline \multirow{2}{*}{ Type of aneuploid } & \multirow{2}{*}{$\begin{array}{c}\text { No. of } \\
\text { cells }\end{array}$} & \multicolumn{6}{c}{ Average number/cell } \\
\cline { 4 - 8 } & studied & I & II & III & IV & V & VI \\
\hline Double trisomic 1 & 90 & 0.47 & 5.47 & 1.35 & - & - & - \\
Double trisomic 2 & 75 & 1.40 & 6.40 & 0.60 & - & - & - \\
Tetra-trisomic & 40 & 3.45 & 4.40 & 0.85 & 0.55 & - & - \\
Hypotriploid & 75 & 4.52 & 3.67 & 1.99 & 0.29 & - & - \\
$\begin{array}{l}\text { Hypertriploid } \\
\text { Hypotetraploid (27-chromosomes } \\
\text { variant) }\end{array}$ & 90 & 2.34 & 2.96 & 4.43 & 0.10 & & \\
$\begin{array}{c}\text { Hypertetraploid (29-chromosomes } \\
\text { variant) }\end{array}$ & 66 & 7.15 & 6.21 & 1.27 & 0.86 & 0.03 & - \\
$\begin{array}{c}\text { Hypertetraploid (30-chromosomes } \\
\text { variant) }\end{array}$ & 46 & 7.17 & 8.83 & 0.83 & 1.92 & - & - \\
\hline
\end{tabular}

Tetra-trisomic

Among the progeny of an open-pollinated triploid, one plant was found to possess 17 chromosomes with highly reduced vigour and fertility. This plant mostly formed a chain or ring of 4 chromosomes alongwith $1^{\mathrm{III}}+5^{\mathrm{II}}$ at diakinesis/MI. A high frequency of PMCs $(40 \%)$ were either associated with $5^{\mathrm{II}}+1^{\mathrm{III}}+1^{\mathrm{IV}}$ or with $2^{\mathrm{I}}+4^{\mathrm{II}}+1^{\mathrm{III}}+1^{\mathrm{IV}}$ (Fig. 4 ) at diakinesis/ MI (Table 1). Though $2^{\mathrm{I}}+1^{\mathrm{III}}+1^{\mathrm{IV}}$ with $4^{\mathrm{II}}$ was more predominant but the presence of $4^{\mathrm{I}}+$ $5^{\mathrm{II}}+1^{\mathrm{III}}$ or $2^{\mathrm{I}}+6^{\mathrm{II}}+1^{\mathrm{III}}$ in certain PMCs indicates that a quadrivalent has been broken either into $4^{\mathrm{I}}$ or into $2^{\mathrm{I}}+1^{\mathrm{II}}$ in these PMCs (Table 1). Eight univalents were also observed in $25 \%$ of cells which have possibly arisen after conversion of bivalents/quadrivalent into univalents at MI (Fig. 5).

Distribution of $9-8$ was the most frequent at anaphase $I$, followed by $9-1-7,7-2-8,9-2-6$ (Fig. 6) and others (Table 2).

Hypotriploid

A dwarf plant with 19-chromosomes (hypotriploid) was isolated in the progeny of a triploid. Barring tiller number and panicle girth, other morphological attributes of this stock were highly reduced as compared to those of parental triploid and normal disomic sibs. In addition, the panicles of this aneuploid resembled with that of sorghum.

This plant showed a maximum association of $3^{\mathrm{II}}+3^{\mathrm{III}}+1^{\mathrm{IV}} /$ cell at diakinesis. The frequency of univalents/cell was comparatively high (Table 2). 
Loose pairing followed by reduced chiasmata frequency, precocious disjunction, lack of coorientation, unequal distribution, formation of univalent laggards and their subsequent early division into chromatids at AI (Figs. 7 to 12) and bridge formation at AII are the characteristic anomalies of this stock. The extreme meiotic anomalies like formation of many univalent laggards and their precocious division at anaphase I (Fig. 12) was also observed in majority of cells (Table 2) which were never seen in parental triploid. It has shown complete pollen and ovule sterility.

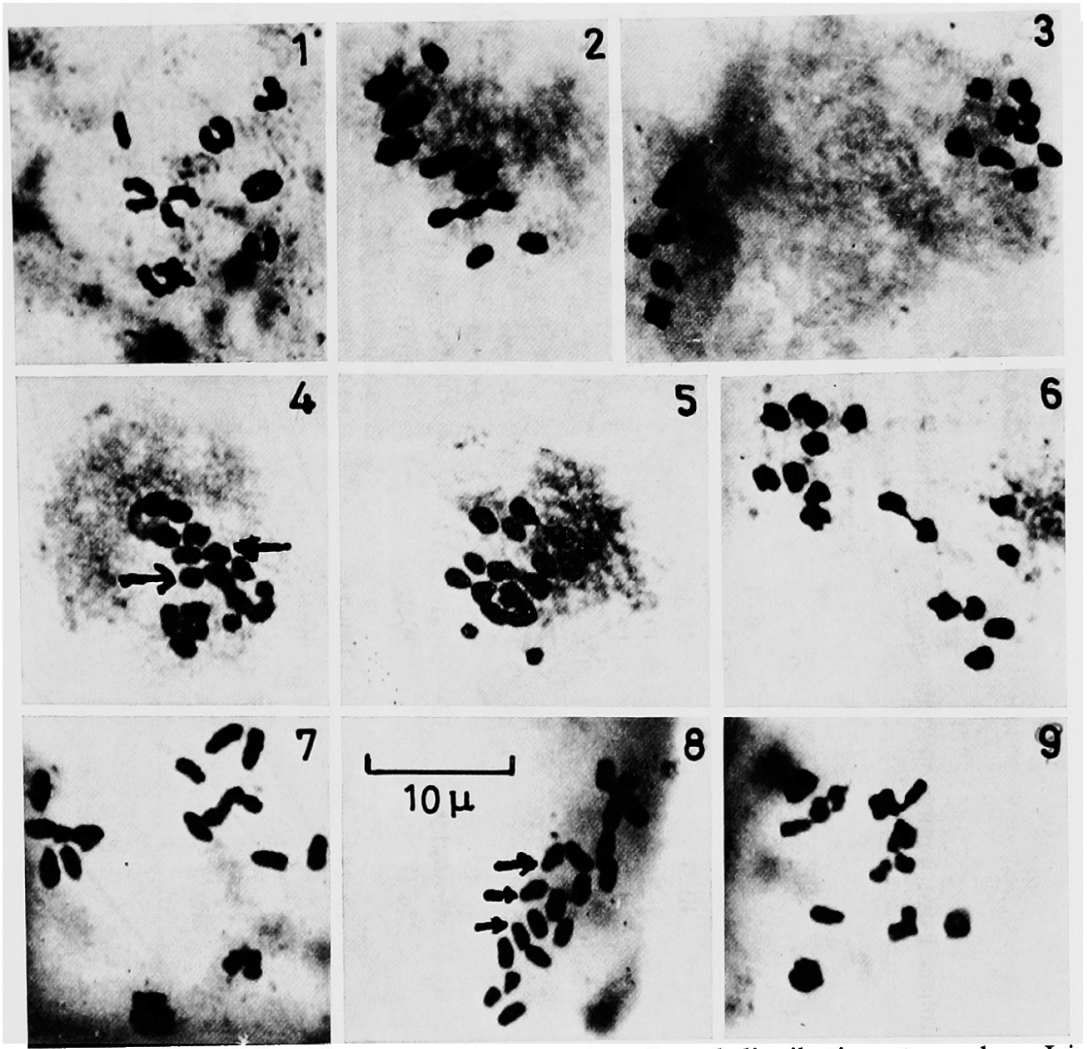

Chromosome associations at diakinesis and metaphase $I$, and distribution at anaphase $I$ in aneuploids of pearl millet. (Figs. 1-27). Figs. 1-9. 1-3: double trisomics. 1, diakinesis, $1^{\text {III }}$ (4-shaped) $+6^{\mathrm{II}}+1^{\mathrm{I}} . \quad 2$, metaphase I, $1^{\mathrm{III}}$ (rod shaped) $+5^{\mathrm{II}}+3^{\mathrm{I}} . \quad 3$, anaphase I, 9: 7 distribution 4-6: Tetra-trisomic. 4, diakinesis, $1^{\mathrm{IV}}$ (upper arrow) $+1^{\mathrm{III}}$ (lower arrow) $+4^{\mathrm{II}}+2^{\mathrm{I}}$. 5, metaphase I, IV $+2^{11}+9^{\text {I }}$. 6, anaphase I, 9: 2 (late distribution): 6 distribution. 7-12: Hypotriploid. 7, diakinesis, $1^{\mathrm{III}}+5^{\mathrm{II}}+6^{\mathrm{I}}$. 8 , metaphase $\mathrm{I}, 1^{\mathrm{IV}}+3^{\mathrm{III}}$ (arrow) $+3^{\mathrm{II}}$ showing loose association.

9, metaphase I, $2^{\mathrm{III}}+6^{\mathrm{II}}+1^{\mathrm{I}}$.

\section{Hypertriploid}

The hypertriploid could be distinguished from trisomic maternal sibs by most (if not all) visible morphological characters. The microsporocytes at metaphase I showed a high frequency of trivalents ranging from zero to seven per cell. There was a wide variation in the observed chromosome associations (Figs. 13 to 18) and 20 different types of configurations were found in ninety cells. The maximum chromosome associations observed were $6^{\mathrm{III}}+1^{\mathrm{IV}}$ as well as $7^{\mathrm{III}}+1^{\mathrm{I}}$ and the minimum was $8^{\mathrm{I}}+7^{\mathrm{II}} /$ cell, respectively (Table 1 ). In certain PMCs, however, the chromosome associations of either $5^{\mathrm{II}}+4^{\mathrm{III}}$ or $1^{\mathrm{I}}+6^{\mathrm{II}}+3^{\mathrm{III}}$ or $2^{\mathrm{I}}+7^{\mathrm{II}}+2^{\mathrm{III}}$ or $8^{\mathrm{II}}+$ $2^{\text {III }}$ were observed. Some of these associations included one and others included two 


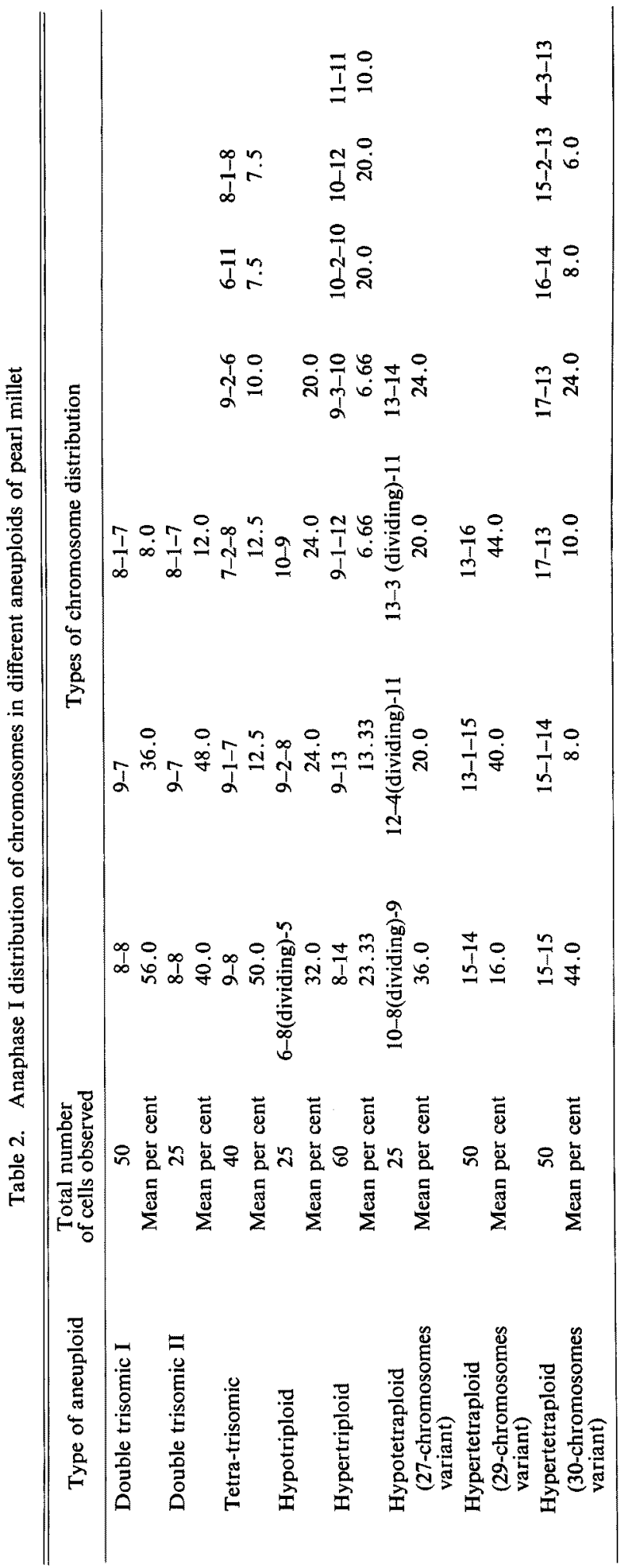


achiasmatic bivalents.

The observed quadrivalent frequency of 0-1 per cell was lower than the expected of one per cell. The quadrivalent forming chromosomes often formed two bivalents (in approx. $46 \%$ of cells), some times $1^{\mathrm{I}}+1^{\mathrm{III}}$ (in $36 \%$ of cells) and very rarely $2^{\mathrm{I}}+1^{\mathrm{II}}$ or $4^{\mathrm{I}}$. Most of the univalents appeared to originate from trivalent forming chromosomes. Nearly sixty six per cent of the cells had 4 to 6 trivalents, $55 \%$ had 3 to 5 bivalents and about $76 \%$ showed 1 to 4 univalents. The chiasma number ranged from 12 to 26 with mean chiasmata of $13.40 \pm 0.24$ per cell or 0.60 per chromosome.

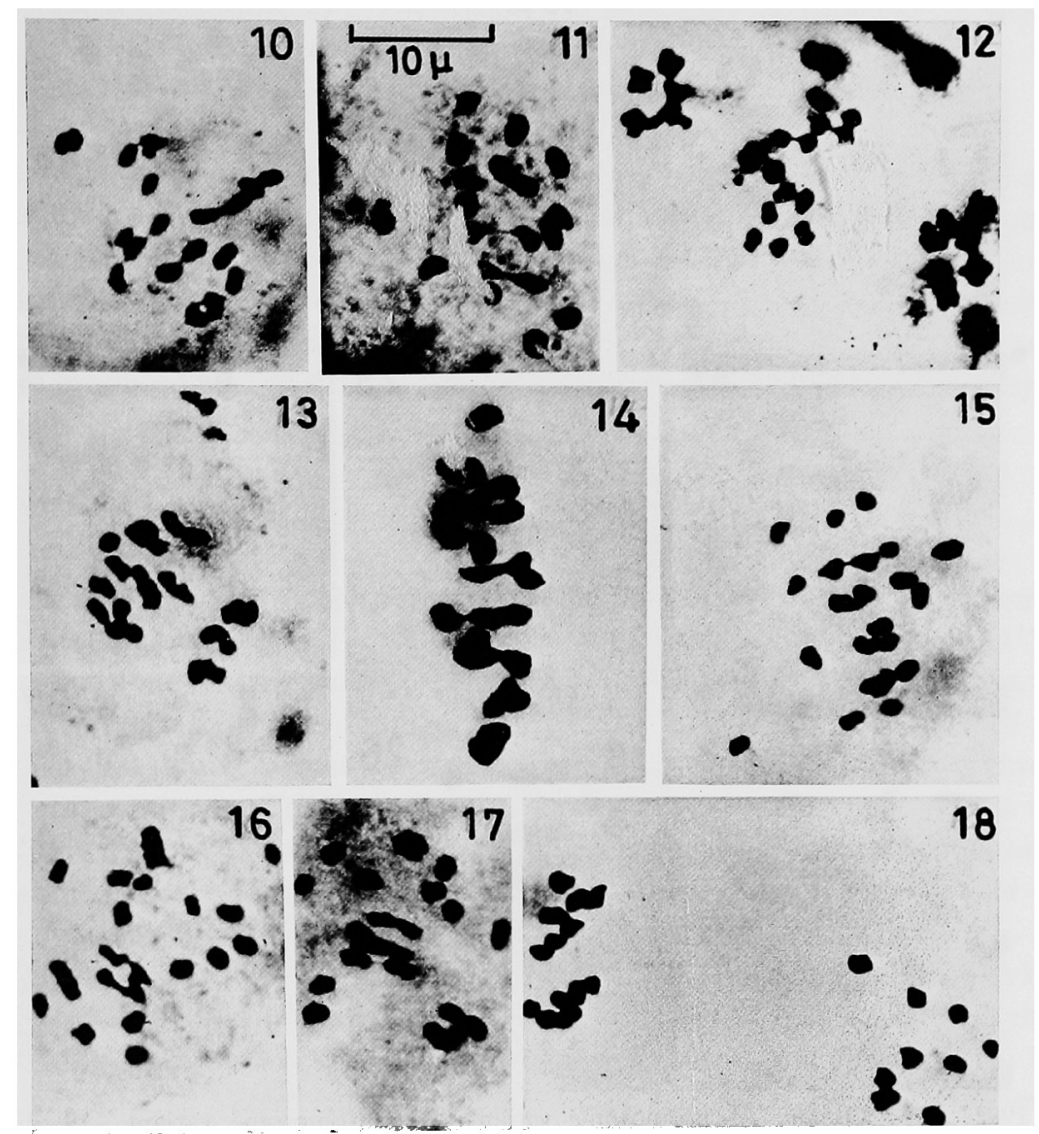

Figs. 10-18. 10, metaphase I, $1^{\mathrm{IV}}+1^{\mathrm{III}}+4^{\mathrm{II}}+4^{\mathrm{I}} .11$, metaphase $\mathrm{I}, 1^{\mathrm{III}}+3^{\mathrm{II}}+10^{\mathrm{I}} .12$, Anaphase I, 6: $8^{1}$ (showing chromatid separation): 5, 13-18: Hypertriploid. 13 , diakinesis, $2^{\mathrm{III}}+$ $6^{I I}+4^{I}$. 14, metaphase I, $5^{\text {III }}+3^{I I}+1^{I}$. 15 , early anaphase I. 16 , anaphase I, $8: 8$ distribution with late disjunction of $3^{\text {II }}$. 17 , anaphase $\mathrm{I}, 6: 4$ distribution with late disjunction of $6^{11}$. 18 , anaphase I, 13: 9 distribution.

Table 2 resumes the frequency of different types of chromosome distribution encountered at anaphase I (Figs. 16 to 18). Various kinds of segregations such as 9-12, 10-10 and 9-10 with 1, 2 and 3 univalent laggards were observed. The maximum frequency of AI segregation was $8-14$ followed by 10-12 and others. Variation in the pattern of chromosome disjunction thus observed at AI produced diads and tetrads with unequal chromosome numbers; which in turn may produce different aneuploids in the progeny of this plant. Certain PMCs were found to have bivalents with early (Fig. 15) and late disjunctions at AI (Figs. 16 to 17). 
Hypotetraploid (27-chromosomes variant)

The frequency of cells with varying chromosome configurations at diakinesis and MI stages are given in Table 1 (Figs. 19 to 20). This variant showed a higher ferquency of PMCs either with $10^{\mathrm{I}}+1^{\mathrm{II}}+1^{\mathrm{III}} /$ cell or with $11^{\mathrm{I}}+4^{\mathrm{II}}+2^{\mathrm{IV}}$ followed by $12^{\mathrm{I}}+6^{\mathrm{II}}+1^{\mathrm{III}} /$ cell. The univalents/cell varied from 0 to 12 while the number of bivalents and trivalents/cell ranged from 4 to 10 and 1 to 4 , respectively. As compared to other configurations, the frequency of quadrivalents/cell was considerably low which ranged between 1 to 3/cell. As compared to others, the

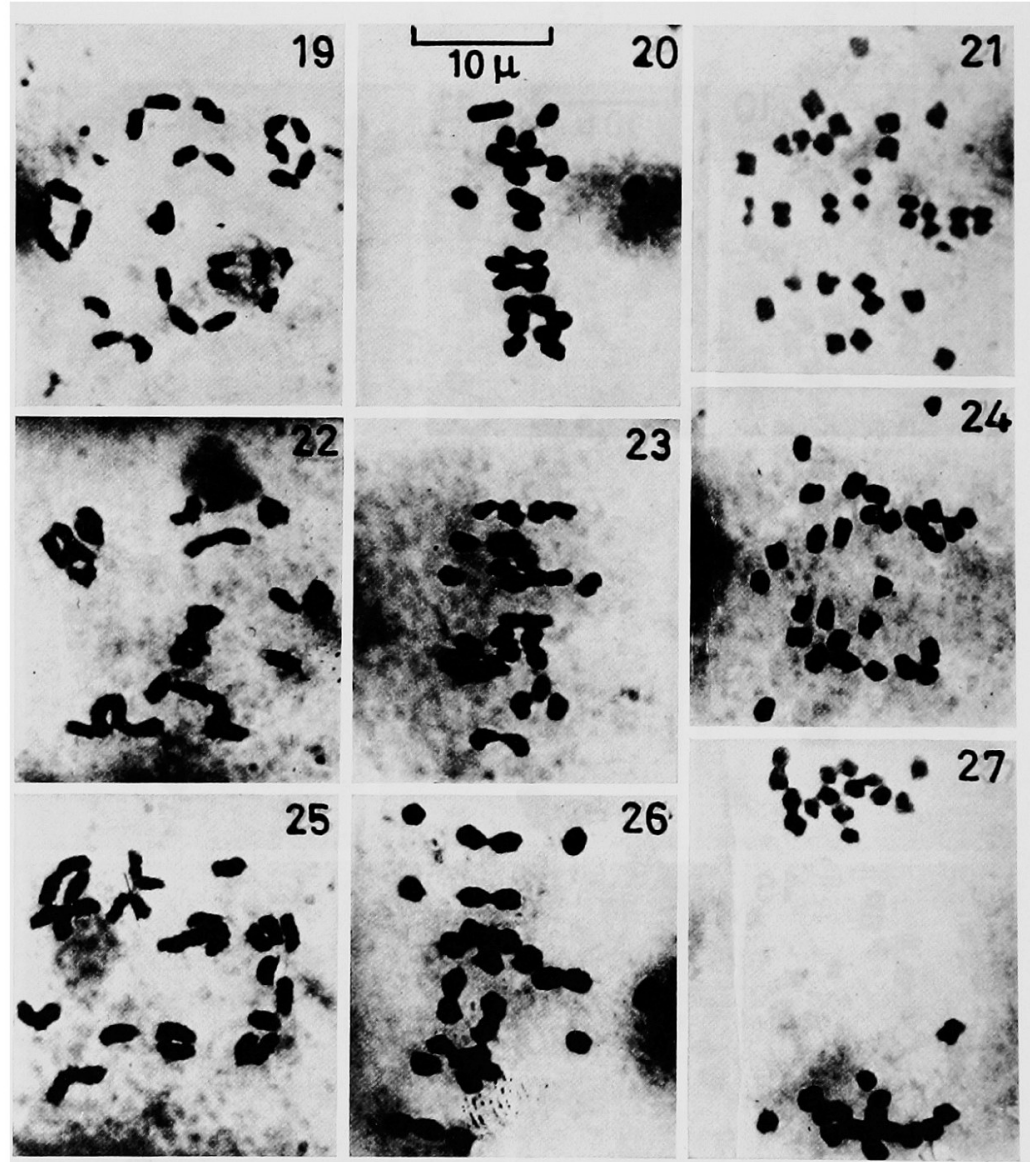

Figs. 19-27; 27-, 29- and 30-chromosome variants. 27-chromosome variant. 19, diakinesis, $1^{\mathrm{V}}+1^{\mathrm{IV}}+2^{\mathrm{III}}+5^{\mathrm{II}}+2^{\mathrm{I}}$. 20, metaphase I, $9^{\mathrm{II}}+9^{\mathrm{I}}$. 21, anaphase I, 10: $8^{\mathrm{I}}$ showing chromatid separation: 9, 29-chromosomes variant. 22, diakinesis, $3^{\mathrm{IV}}+1^{\mathrm{III}}+6^{\mathrm{II}}+2^{\mathrm{I}} .23$, metaphase I, $1^{\mathrm{III}}+10^{\mathrm{II}}+6^{\mathrm{I}}$. 24, anaphase I, 16: 13 distribution, 30-chromosomes variant. 25 , diakinesis, $1^{\mathrm{IV}}$ $+3^{\mathrm{III}}+7^{\mathrm{II}}+3^{\mathrm{I}} . \quad 26$, metaphase I, $1^{\mathrm{IV}}+1^{\mathrm{III}}+8^{\mathrm{II}}+7^{\mathrm{I}} .27$, anaphase I, 15: 15 distribution.

chiasma frequency per cell in this case was minimum $(15.13 \pm 0.65 /$ cell $)$ and which ranged from 11 to $20 /$ cell. This variant was unusually associated with frequent division of univalent laggards (3 to 8 ) (Fig. 21) alongwith unequal separation of chromosomes at AI.

Hypertetraploids (29- and 30-chromosome variants)

The maximum percentage of chromosomes have formed bivalents in both cases which led to an increase in the number of chiasmata/cell. In case of 30-chromosome type, the frequency of pentavalent association was relatively higher as compared to those of other variants. But 
a rare occurrence of one hexavalent in certain cells also indicates the hexasomic nature of one chromosome as two pentavalents were never observed in a single cell (Table 1, Figs, 22-27). The parental tetraploid $\left(\mathrm{C}_{1}\right)$ of 29 -chromosome variant also showed the maximum distribution of 14-14 followed by 13-15 at AI. But, tetraploid producing 30-chromosome type on selfing, was noticed with maximum disjunction of $14-14$ followed by $12-16$ at AI. Thus, these hypertetraploids were originated due to predominace of foresaid distribution of chromosomes noticed in their corresponding tetraploid parents.

At anaphase I, 13-16 distribution was maximum (Fig. 24) followed by 13-1-15 and 14-15 in the 29-chromosome variant while 30-chromosome type was seen with varying kinds of unequal disjunction at AI (Table 2). The maximum frequency of cells (44\%) showed equal distribution (15-15) followed by some unequal distribution like 16-14 and 17-13. But other distributions like 15-1-15, 15-2-13 and 14-3-13 were relatively less frequent.

Fertility

The pattern of AI distribution has a strong bearing on the fertility of pollen and ovules in different variants. Mostly irregular distributions and frequent precocious splitting of univalent laggards in the hypotetraploid has led to the high inviability of gametes. Likewise, in case of 30-chromosome variant, often occurrence of aneuploid gametes may result into the complete sterility of both pollen and ovules. However, in 29-chromosome type, gametes with $\mathrm{n}=14,15$ were produced in considerable amount which probably led to some fertility of pollen, ovules and seeds set rarely.

\section{Discussion}

The isolation of double trisomics in the progeny of triploid was reported previously by Gill et al. (1970a) and Sai Kumar et al. (1981). The complete absence of $6^{\mathrm{II}}+1^{\mathrm{IV}}$ or $8^{\mathrm{II}}$ in cytological preparations of these stocks excludes the possibility of their becoming as tetrasomic types. The occurrence of a high frequency of $5^{11}+2^{\text {III }}$ and a rare frequency of univalents with bivalents in first double trisomic is indicative of involvement of both extra chromosomes as the longer chromosomes of the set. Contrarily, the low frequency of trivalents and a high frequency of univalents in the second one suggest that at least one extra chromosome of this stock was a shorter one. The equal $(8: 8)$ and unequal $(9: 7)$ distribution should be equally frequent in both kinds of associations of cells i.e., either with $5^{\text {II }}+2^{\text {III }}$ or with $6^{11}+1^{\text {III }}+1^{I}$ in prophase I. However, it seems as though there is built in division mechanism which results in a tendency for equal number of chromosomes to go to the poles (Michel and Burnham 1969). The high frequency of equal disjunction leading to formation of hyperploid $(n+1)$ gametes and involvement of both longer extra chromosomes in first stock resulted into complete sterility of pollen and seeds. However, no double trisomic could be recovered probably due to lack of simultaneous transmission of both extra chromosomes in the small progeny population of second trisomic studied. All the four double trisomics studied in this case differed morphologically from each other which indicates that they possibly involved different extra chromosomes of the complement.

As the extra chromsomes are added to a complement, the plant vigour, pollen and ovule fertility are reduced with remarkable difference as compared to their diploid sibs. The tolerance of only two to four chromosomes have been reported in sugar beet (Levan 1942), sorghum (Price and Ross 1957), barley (Tsuchiya 1960) and pearl millet (Gill and Virmani, 1971; Sai Kumar et al. 1981, 1982). The occurrence of a high frequency of PMCs $(40 \%)$ with $5^{\mathrm{II}}+1^{\mathrm{III}}+1^{\mathrm{IV}}$ or with $2^{\mathrm{I}}+4^{\mathrm{II}}+1^{\mathrm{III}}+1^{\mathrm{IV}}$ at diakinesis/MI in 17 -chromosome variant indicates that this plant is tetra-trisomic in nature viz., tetrasomic for one member and trisomic for another member of set. Simultaneously, a complete absence of PMCs with $2^{\text {III }}$ but regular occurrence of quardiva- 
lent in majority of cells $(55 \%)$ excludes the possibility of its becoming as a triple trisomic.

During chromosomes disjuction in triploid plant all the three doses of one chromosome and two out of three doses of other member and single dose of remaining members of the set might have moved to the same pole and formed a gamete with $\mathrm{n}=10$ chromosomes. On fertilization of such gametes with a normal pollen, a tetratrisomic plant would result in the progeny of a triploid. Gill et al. (1970) have reported the maximum limits of tolerance of three extra chromosomes (triple trisomic) in pearl millet. But presence of one tetra-trisomic plant in this study suggests that plants with 4 doses of one chromosome (tetrasomic) in addition to trisomic condition of other member of the set can also be viable in pearl millet.

In case of hypotriploid, the presence of $3^{\text {III }}+1^{\text {IV }}$ in addition to $3^{\text {II }}$ in majority of cells could be explained on the assumption that the plant was tetrasomic for one chromosome and trisomic for three different chromosomes of the complement. Thus, this hypotriploid may also be referred to as tetra-triple trisomic which has been reported for the first time in pearl millet. The large number of univalent chromosomes at early metaphase could suggest that precocious separation of chromosomes alone could not account for the occurrence of univalent and that genetic causes are more likely to play an important role in their production. A disproportionate increase in doses of different members of the genome, as found in this aneuploid, might have caused drastic genetic imbalance leading to gross meiotic abnormalities and complete sterility to pollen and ovules. The characteristic anomalies of this stock correspond well with the aneuploids of ryegrass (Ahloowalia 1972).

In hypertriploid, the study of chromosome behaviour at MI showed that the plant was near triploid $(2 n=22)$ which was trisomic for six chromosomes and tetrasomic for one. The frequent occurrence of $6^{\text {III }}+1^{1 v}$ could amply suggests this view. This plant could originate when an aneuploid egg cell $(n=15)$ was fertilized by a haploid male gamete $(n=7)$. Usually the transmission of aneuploidy is better through the female than the male gametes. Since the female parent of this hypertriploid was a partially desynaptic trisome, which also formed the unreduced gametes $(n=15)$ in rare frequency ( $2 \%$ cells). The hypertriploid is possible if such aneuploid egg cell $(n=15)$ is fertilized by the haploid pollen.

The hypertriploid plant originated from a partially desynaptic trisomic crossed with normal diploids and hence had a (ds) gene which would further account for the higher frequency of univalents at MI. Ahloowalia (1970) reported a case of hypertriploid ryegrass obtained in the progeny of a diploid desynaptic seed parent which had been open pollinated with normal diploids and desynaptic tetraploid clones where aneuploid $(n=15)$ pollens were found to be functional.

The chromosome configurations of $5^{11}+4^{\mathrm{II}}, 1^{1}+6^{\mathrm{II}}+3^{\mathrm{II}}, 2^{\mathrm{I}}+7^{\mathrm{II}}+2^{\mathrm{II}}$ and $8^{\mathrm{II}}+2^{\mathrm{III}}$ were unexpected if a quadrivalent in all these cases forms $2^{\mathrm{II}}$, the unexpected presence of one extra bivalent in first three configurations and two in last one indicate to the pairing of non-homologous chromosomes within the genome. Such types of illegitimate pairing of nonhomologous chromosomes mostly formed achiasmatic bivalents. Jauhar (1968) while discussing the phyletically basic number in Pennisetum, has considered pearl millet as a secondarily balanced diploid species which has been derived from a basic number lower than 7. Also, Jauhar (1970) after noting a low frequency of multivalents (5-, 6- and 8-valents) in a autotetraploid pearl millet presumed that such multivalent associations have resulted either from association of homoeologous chromosomes within the genome or due to presence of small interchanges. In the present hypertriploid plant of pearl millet, a complete lack of hexavalent or two more quadrivalent does not leave much scope for accepting the first view of Jauhar (1970). The alternative possibility for occurrence of unexpected achiasmatic bivalents in this case may be either due to presence of displaced duplication or due to small interchanges within the genome of pearl millet. Myers (1944) found such achiasmatic bivalents in Lolium perenne and stated 
that among the seven chromosomes of the haploid set numerous duplications both within and between chromosomes would be expected. Ahloowalia (1970) also hinted that occurrence of an achiasmatic bivalent in hypertriploid ryegrass (Lolium perenne) is due to presence of displaced duplication between chromosomes of haploid set. It is likely that highly abnormal chromosome distribution at AI coupled with the effect of desynaptic gene may be jointly contributing towards the sterility in the hypertriploid pearl millet. The occurrence of aneuploids in the progenies of induced tetraploids of pearl millet is a parallel example to that reported in induced tetraploids of rye (Hagberg and Ellerstrom 1959), barley and sugarbeet (Rommel, 1963) and ryegrass (Ahloowalia, 1966, 1971). Although tetraploids in Pennisetum have been induced and isolated with colchicine treatment by other workers (Jauhar 1970, Nameeta 1973), the detection of aneuploids in $\mathrm{C}_{2}$ generation has not been documented so far. The presence of aneuploid zygotes with 27-, 29- and 30-chromosomes confirms the functioning and viability of aneuploid gametes. Such gametes may have their origin from chromosome segregation of 13: 15 and 12: 16 observed in the parental tetraploids of $C_{1}$ generation. On this basis, at least three different models could be proposed to account for the origin of aneuploid zygotes: 1) That the gametes with $\mathrm{n}=12,13,14,15,16$ combined in all possible ways to produce the observed zygotes as listed. 2) The gametes with $\mathrm{n}=13,14$ and 15 were the only ones which combined to produce the observed zygotes, and those with $n=12$ and 16 either did not function or were eliminated in competition, since zygotes with $2 n=24,25,31$ and 32 resulting from $12 \times$ $12,12 \times 13,15 \times 16$ and $16 \times 16$ could not be detected in $C_{2}$ generation. 3) That aneuploid gametes functioned only through one side (male or female) and the reciprocal gametes were always the normal $(n=14)$ types, thus no reconstituted 28 -chromosome types $(13 \times 15)$ and $(12 \times$ 16) would be expected. In this model, since the transmission of normal gametes will equal to one, the frequency of aneuploid zygotes would represent the transmission of aneuploid gametes. The first two hypotheses do not seem to be correct one, since the observed number of tetraploids was far greater than the expected. Further, the last of three bypotheses seems to fit the observed meiotic behaviour of 27- and 29-chromosomes aneuploids. All the observed MI configurations in the aneuploids agreed with the model that the aneuploid zygotes originated from aneuploid $\times$ normal matings $(13 \times 14$ and $15 \times 14)$ rather than from mating of two aneuploid gametes $(12 \times 15$ and $13 \times 16)$. Perhaps most of the aneuploid gametes were transmitted through female side. This case of aneuploid production through transmission of aneuploid egg cells in pearl millet is parallel to that of aneuploids produced in the tetraploid vs. diploid and near triploid vs. diploid crosses of ryegrass (Ahloowalia 1971, 1982). The orgin of specific aneuploid depends upon the frequent occurrence of specific type of aneuploid gametes found in the corresponding parental tetraploids. For example, 13-15 and 14-14 distributions were mostly frequent in parental tetraploids $\left(C_{1}\right)$ of 27 -chromosomes variant. Similarly, two parental tetraploids of 29 - and 30- chromosome variants were highly associated with 14-14, 13-15 and 12-16, 14-14 distributions, respectively. Occasionally, genotypes favour the survival of more than one chromosome imbalance and hence the occurrence of one 30-chromosomes variant in the tetraploid progeny may be a case of rare event.

With progressive increase in the chromosome dosage of aneuploids varying from 27 - to 30 , an associated decrease in the morpohology and fertility of these variants could not be observed as the fertility of 29-chromosome type was relatively higher than those of other variants. This observation, therefore, suggests that different chromosomes of the genome were possibly involved in these aneuploids. In both hypertetraploids, the quadrivalent farming chromosomes are mostly broken down into bivalents. Thus, the presence of $14^{\mathrm{II}}+1^{\mathrm{I}}$ in a number of PMCs of 29-chromosome variant as well as a high frequency of bivalents observed in other hypertetraploid suggest for "preferential pairing". Moreover, it apppears that diploidization in these variants has been induced probably due to accumulation of certain modifiers in the advanced genera- 
tion of selected tetraploids. A case of "strong" preferential pairing has also been noted in an aneuploid $(2 \mathrm{n}=25)$ of ryegrass (Ahloowalia 1966).

\section{Summary}

Various chromosomal variants like double trisomics, tetratrisomic, hypo- and hyper-triploids as well as hypo-and hyper-tetraploids isolated in pearl millet $(2 n=14)$ were studied for their origin, cytomorphology and fertility.

These aneuploids were distinguishable from their diploid sibs by their reduced plant height, leaf length, width, panicles length and girth and a high degree of sterility. The cytological investigation reveals the involvement of both longer extra chromosomes in first double trisomic whereas in second trisomic at least one extra chromosome was the shorter one. In tetratrisomic plant $40 \%$ PMCs occurred with a chain or ring of 4 chromosomes along with $1^{\text {III }}+$ $5^{\mathrm{II}}$ at diakinesis and MI. In hypotriploid (19-chromosomes) plant, more number of univalents/ cell were recorded while hypertriploid (22-chromosomes) carried more number of trivalents at AI as compared to other categories. Aneuploids with 27-, 29- and 30-chromosomes were isolated with a low frequency in the progenies of induced tetraploids in $\mathrm{C}_{2}$ generation. These aneuploids were apparently recovered through transmission of aneuploid egg cells having different chromosome numbers. From this study some inferences have been drawn regarding the genomic structure of pearl millet and the probable cause of "preferential pairing" noted in specific aneuploids has also been discussed.

\section{References}

Aastveit, K. 1963. The relation between fertility and cytological properties in autotetraploid rye. Genetics Today, Proc. XI Intern. Cong. Genet. 1: 214.

Ahloowalia, B. S. 1966. Chromosome pairing in aneuploid ryegrass. Heredity 57 : 129-134.

- 1970. Chromosome behaviour in a hypertetraploid plant of ryegrass. Theor. Appl. Genet. 40: 138-142.

- 1971. Frequency, origin and survival of aneuploids in tetraploid ryegrass. Genetics 42: 129-138.

- 1972. Trisomics and aneuploids of ryegrass. Theor. Appl. Genet. 42: 363-367.

- 1982. Aneuploids of perennial ryegrass (Lolium perenne L.). Euphytica 31: 103-111.

Ellerstrom and Sjodin, J. 1966. Frequency and vitality of aneuploids in a population of tetraploid red clover. Hereditas 55: 166-182.

Gill, B. S. and Virmani, S. S. 1971. Triple trisomic in pearl millet. Curr. Sci. 40: 22.

-, Virmani, S. S. and Minocha, J. L. 1970. Aneuploids in pearl millet. Experientia 26: 1021.

Hagberg, A. and Ellerstrom, S. 1959. The competition between diploid, tetraploid and aneuploid rye. Hereditas 45: 369-416.

Hermsen, J. G. Th. 1970. Basic information for the use of primary trisomics in genetic and breeding research. Euphytica 19: 125-140.

Jauhar, P. P. 1968. Inter-and intra-genomal chromosome pairing in an interspecific hybrid and its bearing on basic chromosome number in Pennisetum. Genetica 39: 360-370.

- 1970. Chromosome behaviour and fertility of the raw and evolved synthetic tetraploids of pearl millets (Pennisetum typhoids Stapf E.t Hubb). Genetica 41: 407-424.

Khush, G. S. 1973. Cytogenetics of Aneuploids. Academic Press, New York.

Levan, A. 1942. The effect of chromosomal variation in sugarbeets. Hereditas 28: 345-399.

Meijer, E. G. M. and Ahloowalia, B. S. 1981. Effect of genetic background on trisomy in ryegrass. Chromosoma 84: 451-455.

Michel, K. E, and Burnham, C. R. 1969. The behaviour of nonhomologous univalents in double trisomics in maize. Genetics 63: 851-864.

Myers, W. M. 1944. Cytological studies of triploid perennial ryegrass and its progeny. J. Heredity 35: 17-23.

Nameeta, W. M. 1973. Establishment of aneuploids and their use in pearl millet (Pennisetum typhoids (Burm) S. and H.) improvement. Ph. D. Thesis submitted in Meerut University, India.

Price, M. E. and Ross, W. M. 1957. Cytological study of triploid $\times$ diploid cross of Sorghum vulgare Pers. Agron. J. 49: 237-240. 
Rajhathy, T. 1975. Trisomics of Avena strigosa. Can. J. Genet. Cytol. 17: 151-166.

Riley, R, and Law, C, N. 1965. Genetic variation in chromosome pairing. Adv. Genet. 13: 57-114.

Rommel, M. 1963. Aneuploids in some artificially induced polyploids of cultivated plant. Genetics Today, Proc. 11th Intern. Cong. Genet. 1: 213-214.

Sai Kumar, R, Singh, U. P., Singh, R. B. and Singh, R. M. 1981. Cytomorphological behaviour of double trisomic in pearl millet (Pennisetum americanum (L.) K. Schum). Curr. Sci. 50: 906-908.

,,--- and -1982 . Cytological behaviour of a tetra-trisomic plants in pearl millet (Pennisetum americanum (L.) K. Schum. Curr. Sci. 51: 376-378.

,,--- , and -1983 . Cytomorphological behaviour and origin of aneuploids in tetraploid pearl millet (Pennisetum americanum (L.) K. Schum). Cytologia 48: 379-387.

Sears, E. R. 1956. The transfer of leaf-rust resistance from Aegilops umbellulata to wheat. Brookhaven Symp. Biol. 92: 1-22.

Tsuchiya, T. 1960. Cytogenetic studies in trisomics in barley. Jap. J. Bot. 17: 177-215. 